\title{
Eş Zamanlı Topla Dağıt Araç Rotalama Problemi için İki Aşamalı Bir Çözüm Yöntemi Önerisi
}

\author{
A Two-Stage Solution Method for Vehicle Routing Problem with Simultaneous Pick-up and \\ Delivery
}

\author{
Serap ERCAN CÖMERT ${ }^{1}$ (D) , Harun Reşit YAZGAN1 ${ }^{1}$, Nuran GÖRGÜLÜ1 ${ }^{1}$ \\ ${ }^{1}$ Sakarya Üniversitesi, Endüstri Mühendisliği Bölümü, 54100, Sakarya, Türkiye
}

$\ddot{O} \mathbf{z}$

Bu çalışmada, araç rotalama problemlerinin türlerinden olan eş zamanlı topla dağı araç rotalama problemi ele alınmıştır. Eş zamanlı topla dağıt araç rotalama problemi (EZTDARP); müşterilerin taleplerine göre dağıtım yaparken aynı zamanda toplama işleminin de yapıldığı bir araç rotalama problemi çeşididir. Ele alınan problemin çözümü için iki aşamalı bir çözüm yöntemi önerilmiştir. İlk aşamada, kümeleme analizi yöntemleri (K-Means ve K-Medoids algoritmaları) kullanılarak müşteriler kümelenecek, ikinci aşamada ise aynı küme içinde olan müşterilere yapılacak toplama ve dağıtma işlemi için takip edilecek rota tam sayılı doğrusal programlama yardımıyla belirlenecektir. Sonrasında ANOVA testi yardımıyla kümeleme algoritmalarının etkinliği karşılaştırılacaktır.

Anahtar kelimeler: Eş zamanlı topla dağıt araç rotalama problemi, Kümeleme analizi, K-Means kümeleme algoritması, K-Medoids kümeleme algoritmas1

\begin{abstract}
In this study, vehicle routing problem with simultaneous pick-up and delivery (VRPSPD) as a type of vehicle routing problem is discussed. VRPSPD means pick-up and delivery operations are held on a vehicle route at the same time in order to satisfy the customers' demand. A two-stage solution method is proposed to solve the VRPSPD. At the first stage, customers are clustered using clustering algorithms (i.e. $\mathrm{K}-\mathrm{Means}$ and K-Medoids). Then, the route for the pick-up and delivery operations to the customers inside a cluster, is determined by integer linear programming. Finally, the efficiency of clustering algorithms is compared with the ANOVA test.
\end{abstract}

Keywords: Vehicle routing problem with simultaneous pick-up and delivery, Clustering analysis, K-Means clustering algorithm, K-Medoids clustering algorithm

\section{I.GIRISS}

Küreselleşmenin etkisiyle işletmeler tüm ürünlerini dünyaya sunarken, rakipleriyle rekabet edebilmek için farklılıklarını ortaya koyabilmeleri gerekmektedir. Müşteri memnuniyeti en üst düzeye çıkarılırken, var olan tüm kaynakların verimli kullanılması ve maliyetin azaltılması büyük bir role sahiptir. Maliyetlerin azaltılması için iyi bir dağıtım planı yapılması gerekmektedir. Bu durumda işletmeler araç rotalama problemleri ile karşı karşıya gelmektedirler. Lojistik alanında önemli bir yönetim problemi olan araç rotalama problemi (ARP) temel olarak bir dağıtım noktasından; coğrafi olarak dağılmış müşterilerin taleplerini karşılayacak en uygun rotaların belirlenmesi problemidir. ARP, kısıtlarına (zaman kısıtı, kapasite kısıtı, mesafe kısıtı vb.), yolların durumuna, oluşturulacak rotaların başlama ve bitiş düğümlerine, çevreye göre farklı türlere sahiptir. Bu çalışmada Topla Dağıt Araç Rotalama probleminin (TDARP) bir çeşidi olan Eş Zamanlı Topla Dağıt Araç Rotalama Problemi (EZTDARP) incelenmiştir. Topla Dağıt Araç Rotalama Problemi (TDARP) en çok tersine lojistik uygulamalarında kullanılmaktadır. Gün geçtikçe üretim kaynaklarının tüketimi hızla artarken geri dönüşüm faaliyetlerinin ekonomik etkisi ve 
çevresel sorumluluk bilinci önem kazanmaktadır. Tüketilen ürünlerin geri dönüştürülerek ekonomik değer katan ürünlere dönüştürülmesi, ürünlerin tüketilme ömürlerinin dolması, atıkların yeniden işlenmesi, satın alınan ürünlerin işletmelere geri gönderilmesi ve geri dönüşüm faaliyetlerinde tersine lojistiğin uygulanabilirliğinde araç rotalama problemlerine ihtiyaç duyulmaktadır [1].

Kümeleme analizi, verilerin benzer nesnelerden oluşturulmuş gruplara ayrılması işlemidir. Kümeleme analizi işlemlerinde amaç, kümenin içindeki elemanların birbirlerine benzerliği fazla, kümeler arası benzerliğin ise az olmasıdır. Bir kümeleme analizi yönteminin gösterdiği performans bu prensibi ne derece sağladığıyla doğrudan ilişkilidir [2].

$\mathrm{Bu}$ çalışmada, 78 şubeye sahip bir süpermarket zincirinin ana deposundan şubelerine yapacağı eş zamanlı topla dağıt araç rotalama problemi ele alınmış ve ele alınan problemin çözümü için iki aşamalı bir çözüm yöntemi önerilmiştir. Yöntemin ilk aşamasında, kümeleme analizi yöntemlerinden K-Means ve K-Medoids algoritması kullanılarak müşteriler kümelenmiş, ikinci aşamasında ise kümelenen müşteriler kesin çözüm yöntemlerinden tam sayılı doğrusal programlama modeli yardımıyla rotalanmıştır. Makalenin geri kalan kısmı ise şöyledir; ikinci bölümünde, konu ile ilgili literatür araştırması yapılmış, üçüncü bölümde ARP detaylı bir şekilde incelenmiş ve dördüncü bölümde ise önerilen iki aşamalı çözüm yöntemi anlatılmıştır. Beşinci bölümde uygulama kısmına yer verilmiştir. Son bölümde elde edilen sonuçlar özetlenmiştir.

\section{LITERATÜR ARAŞTIRMASI}

Araç rotalama problemi, bir veya birkaç depoda yerleşmiş olarak bulunan araç filosu ile belirli müşterilere yapılan ürün dağıtımı ve müşterilerden ürünlerin toplanması için gerekli olan rotaların belirlenmesi problemi olarak tanımlanmaktadır [3]. Araç rotalama probleminin ilk defa Dantzig ve Ramser tarafindan 1959 yılında ortaya konmuştur. Dantzig ve Ramser çalışmalarında petrol istasyonlarına benzin dağıtım problemini ele almışlar ve bu problemin çözümü için matematiksel bir model geliştirmişlerdir [4].

ARP'nin özelikleri ve ele alınan kısıtlara göre farklı türleri geliştirilmiştir. Atıkların toplanıp geri dönüşüm tesislerinde kullanılması, müşterilerin aldıkları ürünlerden memnun kalmayıp iade etmesi problemleri topla dağıt araç rotalama problemleri (TDARP) olarak tanımlanmaktadır. TDARP'de her rota ana depoda başlar, her müşteri bir araç tarafindan ziyaret edilir, rotadaki müşterilerin toplam talebi araç kapasitesini aşamaz, her müşterinin toplama ve dağ1tım olmak üzere iki talebi vardır. Dağıtım ve toplama işlemlerinin yapılma durumuna göre önce dağıt sonra topla ARP, karışık topla dağıt ARP ve eş zamanlı topla dağıt ARP olmak üzere üçe ayrılmaktadır. Eş zamanlı topla dağıt araç rotalama problemlerinde (EZTDARP) dağıtım ve toplama işlemleri eş zamanlı olarak gerçekleşmektedir. Araç müşteriye geldiğinde müşterinin talebini teslim ederken depoya gönderilecek malzemeleri de teslim almaktadır [5].

EZTDARP ilk olarak Min [6] tarafindan literatüre kazandırılmıştır. Min [6], gerçek bir kütüphane sistemini inceleyerek kütüphanelerdeki kitapların taşınması üzerine çalışan bir algoritma geliştirmiştir. Bu problem, bir merkez kütüphane ve yirmi iki yerel kütüphane arasındaki kitap dağıtma ve toplama operasyonlarını içermektedir. Bu problem üzerine daha sonrasında çeşitli çalışmalar yapılmıştır. Literatürdeki bu çalışmalar kesin, klasik sezgisel ve metasezgisel yöntemler olarak sınıflandırılabilir.

Kesin çözüm yöntemi ile ilgili çalışmalar incelendiğinde ilk olarak Dell' Amico vd. [7] dal-sınır yaklaşımı temelli, dinamik programlama ve konum uzayı gevşetme prosedürünü geliştirmişler ve EZTDARP'ye çözüm aramışlardır. Önerdikleri yöntem 40 müşteriye kadar optimal çözümü bulabilmektedir. Subramanian vd. [8] çalışmasında EZTDARP için güzergahın ortasında kapasitelerin aşılmamasını sağlayan kısıtlamanın zayıf bir şekilde uygulandığı dal-kesme algoritması geliştirmişlerdir. Wang ve Chen [9] EZTDARP'ye zaman penceresi kısıtını ekleyerek çözümü için 0-1 tamsayılı matematiksel model geliştirmişlerdir. Subramanian vd. [10] ise dal-sınır ve kesme temelli algoritma geliştirerek 100 müşteriye kadar EZTDARP için çözüm bulmuşlardır.

Klasik sezgisel ve metasezgisel çözüm yöntemleri ile ilgili çalışmalar incelendiğinde Dethloff [11], EZDTARP için matematiksel modeli geliştirdiği ve ekleme temelli sezgisel bir algoritma önerdiği görülmektedir. Crispim ve Brando [12], karma ve EZTDARP'lerinin çözümü için tabu arama algoritması ve değişken komşuluk arama algoritmasını birlikle kullanarak melez bir algoritma geliştirmişlerdir. Geliştirilen melez algoritmanın etkinliğini literatürdeki test problemleri üzerinde değerlendirmişlerdir. Nagy ve Salhi [13] çalışmalarında, EZTDARP'nin çözümü için sezgisel algoritmalar önermişlerdir. Önerilen algoritmalar sadece tek depolu değil çok depolu eş zamanlı araç rotalama problemlerinin çözümü içinde kullanılmıştır. Chen [14], çalışmasında EZTDARP için benzetilmiş tavlama, tabu arama ve rota iyileştirme prosedürlerine dayalı bir melez sezgisel yöntem geliştirmiştir. Önerilen yöntemin performansı literatürdeki test problemleri üzerinde değerlendirilmiştir. Elde edilen sonuçlar küçük ölçekli problemler için çok verimli bir şekilde en uygun çözümleri sağlayabildiğini ileri sürmektedir. Ropke ve Pisinger [15], EZTDARP'ye zaman penceresi kısıtını ilave ederek geniş komşuluk araması algoritmasını önermişlerdir. 
Önerilen algoritma literatürdeki 338 problem üzerinde test edilmiş ve bu problemlerde 227'si için en iyi çözümü elde etmiş̧ir. Erbao vd. [16] çalışmalarında, EZTDARP'ye zaman penceresi kısıtını ekleyerek genetik algoritma ve diferansiyel evrim algoritmasından oluşan bir melez algoritma ile çözüm aramışlardır. Önerilen melez algoritmanın performansı test problemleri üzerinde denenmiş ve elde edilen sonuçlar genetik algoritma ve diferansiyel evrim algoritmasına göre daha iyi sonuç verdiği göstermektedir. Ai ve Kachitvichyanukul [17] çalışmalarında EZTDARP'nin çözümü için parçacık sürü optimizasyonu algoritmasını önermişlerdir. Önerilen algoritma üzerinde literatürdeki test problemleri kullanılarak denemeler yapılmıştır. Elde edilen sonuçlar, önerilen algoritmanın diğer algoritmalar ile rekabetçi olduğunu göstermiştir. Gajpal ve Abad [18], EZTDARP ele almıştır. Ele aldığı problemin çözümü için karınca kolonisi algoritmasını kullanmışlardır. Önerilen karınca kolonisi algoritması iki kurallı yerel arama yönteminin dışında yapıcı yöntemler içermektedir. Önerilen algoritmanın performansını ölçmek için literatürde yer alan test problemi örnekleri üzerinde kapsamlı bir çalışma yapılmış ve önerilen karınca kolonisi algoritmasının mevcut algoritmalara göre iyi sonuçlar verdiği ileri sürülmüştür. Zachariadis vd. [19], EZTDARP için Uyarlanabilir Bellek (AM) programlama metodolojisine dayalı bir metasezgisel algoritma geliştirmişlerdir. Metasezgisel algoritmanın performansı 50 ila 400 müşterili test problemleri üzerinde test edilmiş ve elde edilen sonuçlar geliştirilen algoritmanın yüksek kalitede sonuçlar ürettiğini ifade etmektedir. Catay [20], EZTDARP'nin çözümü için yeni bir tasarruf tabanlı görünürlük fonksiyonu ve feromon güncelleme prosedürü kullanan bir karınca koloni algoritması önermiştir. Literatürdeki test problemleri ile yapılan sayısal testler, önerilen yaklaşımın rekabetçi sonuçlar sağladığını ve en iyi bilinen birkaç çözümü geliştirdiğini ileri sürmektedir. Çetin ve Gencer [21], EZTDARP'ye kesin zaman penceresi kısıtını ilave ederek kesin zaman pencereli eş zamanlı topla dağıt araç rotalama problemini tanımlamış ve matematiksel modelini kurmuşlardır. Önerilen model Solomon'un test problemlerinden derlenen problemlerin çözümü için denenmiştir. Sonuçlar incelendiğinde, müşteri say1sı arttıkça problemin zorlaştığı ve optimum çözüm say1sının azaldığı hatta çözümsüz sonuçların elde edildiği ileri sürülmektedir. Mingyong ve Erbao [22], EZTDARP'ye zaman penceresi kısıtını ilave ederek ele almışlardır. Ele aldıkları problemin çözümü için karışık tam sayılı programlama modeli ve geliştirilmiş diferansiyel evrim algoritması önermişlerdir. Önerilen yöntemler test problemleri üzerinde denenmiş ve elde edilen sonuçlar büyük ölçekli problemlerde önerilen sezgisel algoritmanın matematiksel modele kıyasla daha iyi sonuçlar verdiğini ifade etmektedir. Zachariadis vd.
[23] çalışmalarında EZTDARP için adaptif hafıza programlama metodolojisi geliştirmişlerdir. Geliştirilen adaptif hafiza programlama metodolojisi ile Tabu Arama algoritmas1 birleştiğinde yeni geçici çözümler oluşmaktadır. Önerilen yöntemin performası test problemleri üzerinde denenmiş ve elde edilen sonuçlar önerilen yöntemin çok iyi performans sergilediğini ve yeni en iyi çözümler elde ettiğini ileri sürmektedir. Goksal vd. [24], EZTDARP için parçacık sürüsü optimizasyonu (PSO) ve değişken komşuluk arama algoritmasını kullanan melez bir çözüm önermişlerdir. Önerilen melez algoritmanın etkinliği literatürde mevcut olan test problemleri üzerinde yapılan bir deneyle araştırılmıştır. Deneysel sonuçlar, önerilen algoritmanın literatürdeki sezgisel yaklaşımlarla rekabet ettiğini ve en iyi bilinen birkaç çözümü geliştirdiğini ifade etmektedir. Li vd. [25], EZTDARP'ye birden çok depo kısıtını ekleyerek çok depolu eş zamanlı topla dağıt araç rotalama problemini ele almışlardır. Ele aldıkları problemin çözümü için yerel arama yöntemine dayalı uyarlanabilir komşuluk arama algoritmasını geliştirmişlerdir. Deneysel sonuçlar, önerilen yaklaşımın geniş komşuluk arama, parçacık sürüsü optimizasyonu ve karınca kolonisi optimizasyonu yaklaşımı ile elde edilen sonuçlardan daha iyi performansa sahip olduğunu ileri sürmektedir. Kaya [26], EZTDARP için Karınca Koloni Sistemi (KKS) ile Değişken Komşuluk Aramasına (DKA) dayanan melez bir meta-sezgisel algoritma geliştirmiştir. Geliştirilen algoritmanın performansı test problemleri üzerinde denenmiştir. Deneysel sonuçlar önerilen bu yaklaşımın hem çözüm kalitesi hem de CPU süresinde güçlü ve etkili olduğunu kanttlamaktadır. Zhu ve Sheu [27], EZTDARP'de müşterilerin taleplerini stokastik olarak ele almıştır. Ele aldığı problemin çözümü için uyarlanabilir geniş komşuluk araması algoritması geliştirmişlerdir. Geliştirilen algoritmanın etkinliği test problemleri üzerinde denenmiştir.

Literatürde ARP'nin çözümünde kümeleme analizi yöntemlerinin kullanıldığ 1 çalışmalar incelendiğinde ise Nallusamy vd. [28] çoklu gezgin satıcı problemini basit gezgin satıcı problemine dönüştürmek için kümeleme analizi yöntemlerinden K-Means algoritmasını kullandığı görülmektedir. Kümeleme işleminden sonra ise tabu arama ve benzetimli tavlama yöntemlerini kullanarak gezgin satıc1 probleminin çözümünü yapmışlar ve elde edilen sonuçları karşılaştırmışlardır. Çalışkan [29] çok depolu ARP'nin çözümünde karınca kolonisi ile kümeleme algoritmalarını birlikte kullanmış ve toplam maliyeti en aza indirmeyi hedeflemiştir. Şen [30] kapasite kısıtlı ARP'nin çözümü için kümeleme analizi yöntemlerini GA ile destekleyerek yeni bir yaklaşım geliştirmiş̧ir. Bozyer vd. [31] kapasite kısıtlı ARP'nin çözümü için gruplama aşamasında kümeleme analizi tekniklerinden C-means algoritmasının kullanıldığı, 
önce kümele sonra rotala yöntemini önermişlerdir. Cömert vd. [32] sıkı zaman pencereli ARP'nin çözümü için kümeleme analizi tabanlı iki aşamalı bir çözüm yöntemi önermişlerdir. Önerilen yöntemin geçerliliği bir örnek olay üzerinde gösterilmiştir. Ünsal vd. [33], ARP'nin bir alt dalı olan okul servisi rotalama probleminin optimizasyonu için yapay zekâ ve kümeleme analizi teknikleri kullanılarak bir yöntem geliştirmişlerdir. Geliştirilen yöntem Ankara ilindeki bir okula taşımacılık hizmeti veren servis firmasından toplanan rota verileri üzerinde uygulanmış ve elde edilen sonuçların mevcut değerlerden daha iyi olduğu iddia edilmiştir.

Literatür araştırmasında da görüldüğü gibi EZTDARP'nin çözümünde kesin çözüm yöntemlerinin kullanıldığı çalışmalar çok azdır. EZTDARP'de klasik ARP gibi NP-zor problem sınıfına girdiği için problemin kısıt ve değişken sayısı arttığında kesin çözüm yöntemleri kullanılarak çözülmesi zor hatta imkânsız hale gelmektedir. Bu nedenle, bu çalışmada orta ve büyük boyutlu örnekleri çözmek için kullanılabilecek bir iki aşamalı çözüm yaklaşımı önerilmektedir. Önerilen çözüm yöntemi müşterileri kümeleyerek problemin boyutunu küçültmekte ve kesin çözüm yöntemi kullanılarak çözülmesine olanak sağlamaktadır.

\section{EŞ ZAMANLI TOPLA DAĞIT ARAÇ ROTALAMA PROBLEMI}

Araç rotalama en basit tanımıyla, bir veya birden fazla depodan talepleri belirli olan müşterilere ürünlerin dağıtılması ve müşterilerden ürünlerin toplanması için gerekli olan rotaların belirlenmesidir. Birden fazla aşamadan oluşan lojistik sistemine bakıldığında araç rotalama probleminde ürünleri depoya taşıyan firma, siparişlerin toplanarak müşterilere hizmet verildiği depo, ürünleri talep eden müssteri ve ürünlerin müsşerilere dağıtımını sağlayan araç filosu bileşenleri yer almaktadır.

Lojistikte önemli bir yere sahip olan ARP hayat koşullarının sunduğu kısıtlamalar sebebiyle farklı formlar alabilmektedir. ARP, kısitlarına (zaman kısitı, kapasite kısıt1, mesafe kısıtı vb.), yolların durumuna, oluşturulacak rotaların başlama ve bitiş düğümlerine, çevreye göre birçok çeşide sahiptir. Bu çalışmada topla dağıt araç rotalama probleminin (TDARP) bir çeşidi olan eş zamanlı topla dağıt araç rotalama problemi (EZTDARP) ele alınmıştır. Atıkların toplanıp geri dönüşüm tesislerinde kullanılması, müşterilerin aldıkları ürünlerden memnun kalmayıp iade etmesi problemleri TDARP olarak tanımlanmaktadır. TDARP'de her rota ana depoda başlar, her müşteri bir araç tarafindan ziyaret edilir, rotadaki müşterilerin toplam talebi araç kapasitesini aşamaz, her müşterinin toplama ve dağıtım olmak üzere iki talebi vardır. EZTDARP'de dağıtım merkezinden veya depodan hareket eden araç, rotası üzerinde yer alan her müşteriye talep ettiği miktarda ürünü ulaştırdıktan sonra aynı araç ile eş zamanlı olarak müşteriden arz edilen miktarı toplayarak depoya geri döner. Depodan çıkan aracın izlediği rota boyunca ziyaret edeceği müşterilerin dağıtım taleplerinin karşılanacağı ve müşterilerden toplayacağ tüm ürünleri depoya taşıyabileceği şekilde kapasite kontrolü sağlayacağı bir rotalama yapılmalıdır. Her müşteri yalnızca bir kez hizmet görmektedir. Toplama ve dağııımın ayrı ayrı planlandığı araç rotalama problemlerine göre aynı araç tarafından eş zamanlı olarak gerçekleştirilen dağıtım ve toplama faaliyetleriyle kaynakların daha verimli kullanılması ve maliyetlerin azaltılması sağlanmaktadır. Marketlere talep edilen miktarda içeceklerin dağıtımı yapıldıktan sonra aynı marketlerden boş şişelerin geri dönüşüm için toplanması, bu problem tipine örnek olarak verilebilir [5].

Bu çalışmada, Montane ve Galvao [34] ve Ai ve Kachitvichyanukul [17]'un önerdikleri matematiksel modeller esas alınmıştır. EZTDARP'nin matematiksel modeli şu şekildedir:

\section{Dizin Kümeleri ve Parametreler}

$N$ Müşteriler kümesi, $\{1,2,3 \ldots, n\}$

$N_{0}$ Depo ve müstterilerden oluşan düğümler kümesi, $N_{0}=N \bigcup\{0\}$

$V$ Araçlar kümesi, $\{1,2,3 \ldots, m\}$

$Q_{k}$ Araç kapasitesi, $k \in V$

$F_{k}$ Her aracın sabit maliyeti, $k \in V$

$V_{k}$ Birim uzaklık başına değişken maliyet, $k \in V$

$C_{i j}$ i ve j düğümleri arasındaki uzaklık, $i \in N_{0}, j \in N_{0}$

$d_{j}$ j müşterisinin dağıtım talebi, $j \in N$

$p_{j}$ j müşterisinin toplama talebi, $j \in N$

\section{Karar değişkenleri}

$X_{i j k} \quad \mathrm{k}$ nolu araç i'inci düğümden jinci düğüme gidiyorsa 1 , gitmiyorsa 0

$y_{i j k} \quad \mathrm{k}$ nolu araç i düğümünden $\mathrm{j}$ düğümüne gittiğinde $\mathrm{j}$. düğüme ge-

$y_{i j k} \quad$ lene kadar toplanan kümülatif yük miktarı

$z_{i j k} \quad \mathrm{k}$ nolu araç i düğümünden j düğümüne gittiğinde j. düğüme gelene kadar araçta dağıtılacak yük miktarı 


\section{Amaç Fonksiyonu}

Enk Z $=\sum_{k \in V} \sum_{j \in N} \mathrm{~F}_{k} \mathrm{X}_{0 j k}+\sum_{k \in V} \sum_{i \in N_{0}} \sum_{j \in N_{\mathrm{o}}} \mathrm{V}_{k} \mathrm{X}_{i j k} \mathrm{C}_{i j}$

\section{Kisitlar}

$$
\begin{array}{ll}
\sum_{k \in V} \sum_{i \in N_{0}} X_{i j k}=1 & \forall j \in N \\
\sum_{i \in N_{0}} \mathrm{X}_{i p k}-\sum_{j \in N_{0}} \mathrm{X}_{p i k}=0 & \forall p \in N_{0}, \forall k \in V
\end{array}
$$

$$
\sum_{j \in N} \mathrm{x}_{0 j k} \leq 1 \quad \forall k \in V
$$

$$
\mathrm{y}_{0 i k}=0 \quad \forall i \in N, \forall k \in V
$$

$$
\mathrm{z}_{0 i k}=0 \quad \forall i \in N, \forall k \in V
$$$$
\sum_{i \in N_{0}} \sum_{k \in V} \mathrm{y}_{j i k}-\sum_{i \in N_{0}} \sum_{k \in V} \mathrm{y}_{i j k}=p_{j} \quad \forall j \in N
$$$$
\sum_{i \in N_{0}} \sum_{k \in V} z_{i j k}-\sum_{i \in N_{0}} \sum_{k \in V} z_{j i k}=d_{j} \quad \forall j \in N
$$

$$
\sum_{i \in N} \sum_{k \in V} \mathrm{y}_{0 i k}=\sum_{i \in N} p i
$$

$$
\sum_{i \in N} \sum_{k \in V} z_{0 i k}=\sum_{i \in N} d i
$$

$y_{i j k}+z_{i j k}<=Q_{k} X_{i j k} \quad \forall i \in N_{0}, \forall j \in N_{0}, \forall k \in V$

$$
x_{i j k} \in\{0,1\} \quad \forall i \in N_{0}, \forall j \in N_{0}, \forall k \in V
$$$$
y_{i j k} \geq 0 \quad \forall i \in N_{0}, \forall j \in N_{0}, \forall k \in V
$$

$$
z_{i j k} \geq 0 \quad \forall i \in N_{0}, \forall j \in N_{0}, \forall k \in V
$$

Modeldeki (1) numaralı amaç fonksiyonu araç kullanım maliyeti ve toplam seyahat maliyetinin toplamını en küçüklemeyi hedefler. (2) numaralı kısıt tüm dügümlerin sadece bir kez ziyaret edilmesini, (3) numaralı kısıt hizmet verilen düğümün aynı araç ile terk edilmesini sağlar. (4) numaralı kısıt her bir aracın sadece bir rotada yer almasını sağlar. (5) numaralı kısıt aracın topladığı yükü tur başında sıfıra eşitlemektedir. (6) numaralı kısıt aracın dağıtım yükünü tur sonunda sıfıra eşitler. (7) numaralı kısıt araç tarafından toplanılan yükü araç rotası boyunca artarak izlemesini, (8) numaralı kısıt ise aracın dağıtım yükünün araçların rotası süresince azalarak izlemesini sağlar. (9) numaralı kısıt aracın başlangıç noktasına dönüşte tur içinde topladığg yük miktar akışını; tur içinde yer alan dügüumlerin toplam toplama taleplerine eşit olmasını sağlarken (10) numaralı kısıt aracın başlangıç noktasından itibaren tur içinde dağıtılacak yük miktar akışını; tur içinde bulunan düğümlerin toplam dağıtım taleplerine eşit olmasını sağlar. (11) numaralı kısıt rota içindeki herhangi bir müşteride aracın kapasitesinin aşılmamasını sağlamaktadır. (12) numaralı kısıt karar değişkeninin 0-1 tamsayı değerini almasını sağlar. (13) ve (14) numaralı kısıtlar ise işaret kısıtlarıdır.

\section{EZTDARP İÇIN ÖNERILEN İKİ AŞAMALI ÇÖZÜM YÖNTEMI}

1980'lerde, ARP'lerin deterministik olmayan bir polinom-zaman (NP)-zor problemi olduğu kanıtlanmıştır [35]. Yani, optimal bir çözüm bulmak için, ARP'nin bir polinom denklem modeli doğrudan kullanılamaz. Bu nedenle, kesin bir algoritma ile bir çözüme ulaşmak, bazı durumlarda oldukça zor ve/veya imkansız olabilir. Ek olarak, bir ARP'nin çözüm süresi, kısıtlamaların sayısı arttığında katlanarak büyür. Bu nedenle, bu bölümde orta ve büyük boyutlu örnekleri çözmek için kullanılabilecek bir iki aşamalı çözüm yaklaşımı önerilmiştir.

Aşama 1 (Kümeleme Analizi): Müş̧erilerin birbirlerine olan mesafeleri dikkate alınarak kümeleme analizi yöntemleri kullanılarak kümelenmesidir.

Aşama 2 (Rotalama): 1. Aşama sonucunda kümelenen müşteriler için en uygun dağıtım ve toplama rotalarının tam sayılı doğrusal programlama modeli ile oluşturulmasıdır.

Aşama 1: Kümeleme Analizi

Kümeleme, verinin benzer nesnelerden oluşturulmuş gruplara bölünmesi işlemidir. Kümeleme işleminde küme içindeki elemanların benzerlik oranı yüksek, kümeler arası benzerlik oranı ise az olmalıdır. Bir kümeleme yönteminin gösterdiği performans bu prensibi ne derece sağladığıyla doğrudan ilişkilidir. Seçilecek kümeleme yöntemi veri tiplerine ve uygulamanın amacına göre farklılık gösterir [36].

$\mathrm{Bu}$ çalışmada kümeleme analizi yöntemleri olarak K-Means ve K-Medoids algoritmaları kullanılmıştır. Tablo 1 'de en yaygın kullanılan kümeleme analizi yöntemleri gösterilmiştir. 
Tablo 1. Kümeleme analizi yöntemleri [37]

\begin{tabular}{lllll}
\hline \multicolumn{5}{c}{ Kümeleme Analizi Yöntemleri } \\
\hline Aşamalı & Model Bazlı & $\begin{array}{c}\text { Yoğ u n l u k } \\
\text { Bazlı }\end{array}$ & Grid Bazlı & Bölümlemeli \\
\hline $\begin{array}{l}\text { 1.Tek bağ- } \\
\text { lantılı }\end{array}$ & 1.Som & 1.Dbscan & 1.Sting & $\begin{array}{l}\text { 1.K-Ortala- } \\
\text { malar }\end{array}$ \\
\hline $\begin{array}{l}\text { 2.Tam bağ- } \\
\text { lantılı }\end{array}$ & 2.Conwep & 2.,Denclue & $\begin{array}{l}\text { 2.Wave } \\
\text { Cluster }\end{array}$ & 2.K-Medoids \\
\hline & 3.Classfit & 3.Clique & 3.Optics & \\
\hline
\end{tabular}

\subsubsection{K-Means kümeleme algoritması}

1967 yılında J.B. MacQueen tarafından geliştiren en eski kümeleme analizi çeşitlerinden biri K-Means algoritmas1dır. Algoritma daha çok büyük sayıdaki nesnelerden küçük sayıda kümeler oluşturmak için kullanılmaktadır. Nesnelerin her birinin rasgele biçimde kümelere atamaları yapı11r. Sonrasında yapılan bu atamalar K-Means algoritması yardımı ile optimize edilir. K-Means algoritmasının sözde kodu Tablo 2'de verilmiştir [38]:

Tablo 2. K-Means algoritmasının sözde kodu

\begin{tabular}{l}
\hline başla: \\
k küme sayısını belirle \\
Girilen k değeri kadar küme merkezi belirle \\
while (değişiklik varsa) \\
do \\
Küme merkezi dışında kalan verileri mesafelerine göre sınıflandır \\
Sınıflandırmaya göre yeni merkezler belirle \\
\} end while \\
\hline
\end{tabular}

\subsubsection{K-Medoids kümeleme algoritması}

K-Medoids kümeleme algoritması K-Means kümeleme algoritmasının gürültülü ve aykırı değerlere karşı gösterilen aşırı duyarlılığını çözmek için 1990 yılında Kaufman ve Rousseeuw tarafından geliştirilmiştir. Algoritmada kümeyi temsil edecek noktayı bulmak için kümenin merkez noktasında yer alan eleman yeni küme merkezi olarak seçilir ve böylece bazı verilerin küme merkezini kaydırma olasılığı ortadan kalkmış olur. K-Medoids algoritmasının sözde kodu Tablo 3'te verilmiştir [39]:
Tablo 3. K-Medoids algoritmasının sözde kodu

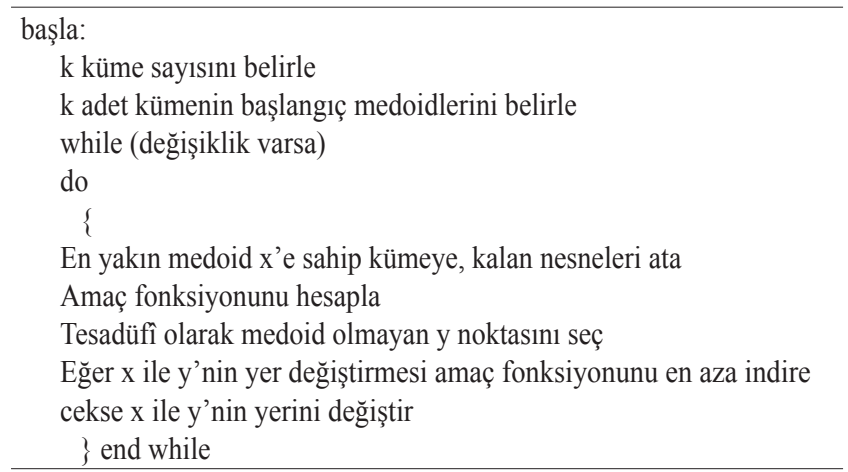

\subsection{Aşama 2: Rotalama}

$\mathrm{Bu}$ aşamada amaç; 1. Aşamanın sonucunda elde edilen kümeler için en uygun dağıtım ve toplama rotalarının oluşturulmasıdır. 1. Aşama sonucunda büyük boyuttaki müş̧eri kümesi küçük gruplara bölüneceğinden dolayı bölüm 3 'te verilen EZTDARP için tam sayılı doğrusal programlama modeli yardımıyla optimal sonuçların bulunması mümkün olacaktır.

\section{UYGULAMA}

Ele alınan problem, merkez seçilen bir depodan müşterilerin taleplerine göre haftalık dağıtım hizmeti verirken eş zamanlı olarak toplama hizmetinin de gerçekleştirilmesini amaçlamaktadır. Müşterilere yapılan dağıtım ve toplama operasyonu sadece hafta içi günlerde gerçekleştirilmektedir. Merkez olarak belirlenen depodan 78 müşteriye hizmet verilecektir. Şubelerin geçmiş üç aylık taleplerinin ortalamaları alınarak 21 haftalık dağıtım ve toplama talep verileri elde edilmiştir. Hizmet verirken kullanılacak araçların kapasitesi eşit olup 40 birimdir. Problemde sevkiyat yapılacak müşteriler dağıtım müşterisiyken aynı zamanda da toplama müşterisidir. Kat edilen rotalarda müşterilerin, dağıtım talepleri ile toplama taleplerinin tümü karşılanmalı ve ziyaret edilen her rotada müşterilerden toplanacak yük miktarı ve müşterilere dağıtılacak yük miktarının toplamı, aracın kapasitesini aşmamalıdır.

Ele alınan problemin 1. haftadaki talep miktarları dikkate alınarak detaylı çözümü aşağıda verilmiştir. 


\subsection{Aşama 1: Kümeleme Analizi}

\subsubsection{K-Means kümeleme algoritması ile kümeleme}

K-Means algoritması, rastgele seçilen $\mathrm{k}$ adet merkez noktayla başlar. Kümelerin içindeki her veri kendisine en yakın kümeye atanır. Eğer kümelerin merkezlerinde değişiklik yoksa algoritmaya son verilir. Çalışmada $\mathrm{k}$ için çeşitli değerler verilerek birçok deneme yapılmıştır. Denemeler sonucunda $\mathrm{k}=11$ değerinin verilmesiyle daha iyi sonuçlara ulaşı1dığı gözlemlenmiştir. 78 adet müşteri, küme içi benzerlikler maksimum, kümeler arası benzerlik minunum olacak şekilde 11 adet kümede sınıflanmıştır.

Tablo 4'te K-Means kümeleme algoritmasına göre kümeleme sonucu her kümenin sahip olduğu müşteriler ve müşterilerin dağıtılacak ve toplanacak toplam ürün talepleri yer almaktadır.

Tablo 4. K-Means kümeleme algoritmasına göre sınıflanan müşterilerin dağıtım ve toplama talepleri

\begin{tabular}{|c|c|c|c|}
\hline Küme & Müşteriler & $\begin{array}{l}\text { Müşterilerin } \\
\text { Toplam Da- } \\
\text { ğıtım Talep- } \\
\text { leri }\end{array}$ & $\begin{array}{l}\text { Müssterilerin } \\
\text { Toplam Top- } \\
\text { lama Talep- } \\
\text { leri }\end{array}$ \\
\hline 1 & $\begin{array}{l}20-21-22-23-25-28-31-33-36- \\
38-39-41-42-44-45-46\end{array}$ & 148 & 124 \\
\hline 2 & $17-18-32-34-35-37-40-43-47-48$ & 92 & 92 \\
\hline 3 & $66-67-68-69-70-71-73$ & 65 & 68 \\
\hline 4 & $49-50-51$ & 36 & 36 \\
\hline 5 & $1-2-4-5-6$ & 54 & 52 \\
\hline 6 & $30-52-53-54-55-56-57$ & 66 & 64 \\
\hline 7 & $72-74-75-76-77-78$ & 51 & 54 \\
\hline 8 & $7-8-9-10-11$ & 66 & 66 \\
\hline 9 & $58-59-61-62$ & 40 & 40 \\
\hline 10 & $60-63-64-65$ & 40 & 42 \\
\hline 11 & $3-13-14-15-16-19-24-26-27-29$ & 88 & 86 \\
\hline
\end{tabular}

\subsubsection{K-Medoids kümeleme algoritması ile kümeleme}

K-Medoids algoritmasında, K-Means algoritmasında olduğu gibi rastgele seçilen k adet sayıyı küme merkezi olarak alınır. Kümeyi temsil edecek olan noktayı bulmak için kümenin en merkez noktasında yer alan elemanı yeni küme merkezi olarak alır. K sayısının değeri için yapılan çeşitli denemeler sonucunda $\mathrm{k}=11$ değerinin diğer denemelerden daha başarılı sonuçlar verdiği görülmüştür.

Tablo 5'te K-Medoids kümeleme algoritmasına göre kümeleme sonucu her kümenin sahip olduğu müşteriler ve müşterilerin dağıtılacak ve toplanacak toplam ürün talepleri yer almaktadır.

Tablo 5. K-Medoids kümeleme algoritmasına göre sınıflanan müşterilerin dağıtım ve toplama talepleri

\begin{tabular}{|c|c|c|c|}
\hline Küme & Müşteriler & $\begin{array}{l}\text { Müşterilerin } \\
\text { Toplam Dağıtım } \\
\text { Talepleri }\end{array}$ & $\begin{array}{l}\text { Müssterilerin } \\
\text { Toplam Top- } \\
\text { lama Talepleri }\end{array}$ \\
\hline 1 & $\begin{array}{l}17-18-20-22-23-25-36-38- \\
41-42-44-45-46-55\end{array}$ & 112 & 110 \\
\hline 2 & $\begin{array}{l}16-19-21-26-27-28-31-33- \\
39-40-43-47-48\end{array}$ & 112 & 112 \\
\hline 3 & $66-67-68-69-70-71-73$ & 65 & 68 \\
\hline 4 & $30-50-51-52-53-54-56-57$ & 86 & 84 \\
\hline 5 & $1-2-3-4-5-6$ & 68 & 66 \\
\hline 6 & $74-76$ & 18 & 20 \\
\hline 7 & $72-75-77-78$ & 33 & 34 \\
\hline 8 & $7-8-9-10-11-12$ & 66 & 66 \\
\hline 9 & $49-58-59-61-62$ & 48 & 48 \\
\hline 10 & $60-63-64-65$ & 40 & 42 \\
\hline 11 & $13-14-15-24-29-32-34-35-37$ & 76 & 74 \\
\hline
\end{tabular}

\subsection{Aşama 2: Rotalama}

Bir önceki aşamada sırasıyla K-Means ve K-Medoids algoritmalarına göre kümelenen müşterilerin dağıtılacak ve toplanacak ürün miktar bilgileri ile birlikte, kurulan tam sayılı doğrusal programlama modeli ile araç rotaları oluşturulmuştur.

Tablo 6'da K-Means algoritmasina göre, Tablo 7'de K-Medoids algoritmasına sınıflanan müşterilere ait rota ve maliyet bilgileri yer almaktadır.

Problemin 21 haftalık talep verileri dikkate alınarak K-Means ve K-Medoids algoritmaları ile çözümü sonucunda elde edilen toplam maliyetler ve algoritmaların CPU süreleri Tablo 8'de verilmiştir. 
Tablo 6. K-Means kümeleme algoritmasına göre sınıflanan müşterilere hizmet eden araçların rota ve maliyet bilgileri

\begin{tabular}{|c|c|c|c|c|c|c|c|}
\hline Küme & 1.Araç Rota & 2.Araç Rota & 3.Araç Rota & 4.Araç Rota & 5.Araç Rota & 6.Araç Rota & Maliyetler (TL) \\
\hline 1 & $79-20-79$ & $79-39-21-25-33-79$ & $79-42-22-79$ & $79-28-23-79$ & $79-36-46-44-38-41-79$ & $79-45-31-79$ & 26540 \\
\hline 2 & $79-47-43-48-40-79$ & $79-35-32-37-34-79$ & $79-17-18-79$ & - & - & - & 14380 \\
\hline 3 & $79-70-66-68-79$ & $79-71-67-73-69-79$ & - & - & - & - & 8530 \\
\hline 4 & $79-50-51-49-79$ & - & - & - & - & - & 3885 \\
\hline 5 & $79-2-6-5-79$ & $79-1-4-79$ & - & - & - & - & 7970 \\
\hline 6 & $79-52-55-30-56-79$ & $79-57-54-53-79$ & - & - & - & - & 8340 \\
\hline 7 & $79-78-72-77-75-79$ & 79-76-74-79 & - & - & - & - & 9845 \\
\hline 8 & $79-11-12-10-79$ & $79-7-9-8-79$ & - & - & - & - & 10500 \\
\hline 9 & $79-58-61-59-62-79$ & - & - & - & - & - & 3335 \\
\hline 10 & $79-63-60-79$ & $79-65-64-79$ & - & - & - & - & 3905 \\
\hline 11 & $79-26-29-19-3-79$ & 79-15-27-16-79 & 79-13-24-14-79 & - & - & - & 14740 \\
\hline
\end{tabular}

Tablo 7. K-Medoids kümeleme algoritmasına göre sınıflanan müşterilere hizmet eden araçların rota ve maliyet bilgileri

\begin{tabular}{lllll}
\hline Küme & 1.Araç Rota & 2.Araç Rota & 3.Araç Rota & Maliyetler (TL) \\
\hline 1 & $79-55-42-45-18-17-79$ & $79-25-38-44-41-22-79$ & $79-20-46-23-36-79$ & 13410 \\
2 & $79-28-19-33-27-40-79$ & $79-26-16-21-39-79$ & $79-47-43-48-31-79$ & 14440 \\
3 & $79-70-66-68-79$ & $79-71-67-73-69-79$ & - & 8530 \\
4 & $79-56-30-57-52-79$ & $79-53-54-51-79$ & $79-50-79$ & 12240 \\
5 & $79-2-3-1-79$ & $79-5-6-4-79$ & - & 8255 \\
6 & $79-76-74-79$ & - & - & 4810 \\
7 & $79-78-72-77-75-79$ & - & - & 5035 \\
8 & $79-11-12-10-79$ & $79-7-9-8-79$ & - & 10500 \\
9 & $79-58-79$ & $79-61-59-62-49-79$ & - & 6390 \\
11 & $79-63-60-79$ & $79-65-64-79$ & - & 3905 \\
\end{tabular}

Tablo 8. Kümeleme algoritmalarına göre toplam maliyet bilgileri ve CPU süreleri

\begin{tabular}{lllll}
\hline Hafta & $\begin{array}{l}\text { K-Means Algorit- } \\
\text { ması Toplam Mali- } \\
\text { yet (TL) }\end{array}$ & $\begin{array}{l}\text { CPU } \\
\text { Süresi } \\
(\mathbf{d k})\end{array}$ & $\begin{array}{l}\text { K-Medoids Algorit- } \\
\text { ması Toplam Mali- } \\
\text { yet (TL) }\end{array}$ & $\begin{array}{l}\text { CPU } \\
\text { Süresi } \\
(\mathbf{d k})\end{array}$ \\
\hline 1 & 119970 & 14,2 & 102150 & 14,6 \\
2 & 109886 & 15 & 103155 & 15,4 \\
3 & 111795 & 15,1 & 111575 & 15,5 \\
4 & 108800 & 14 & 116040 & 14,2 \\
5 & 108190 & 16,4 & 111765 & 15 \\
6 & 112775 & 13,5 & 120450 & 13,9 \\
7 & 126134 & 14,1 & 111990 & 14,5 \\
8 & 113870 & 14,6 & 117295 & 14 \\
9 & 108695 & 14,2 & 138775 & 14,6 \\
10 & 108070 & 15,9 & 107925 & 16,3 \\
11 & 111105 & 13,8 & 114395 & 13 \\
12 & 115760 & 13,5 & 118885 & 13,9 \\
13 & 119395 & 13,7 & 102630 & 14,1 \\
14 & 113330 & 15,6 & 116135 & 15,3 \\
15 & 115324 & 14,5 & 106410 & 14,3 \\
16 & 107645 & 13 & 107645 & 13,4 \\
17 & 114620 & 13,4 & 116165 & 13,1 \\
18 & 108210 & 15,8 & 114920 & 16,1 \\
19 & 110215 & 15,6 & 115605 & 15 \\
20 & 111845 & 14,1 & 114950 & 14,5 \\
21 & 111935 & 14,2 & 112475 & 14,6 \\
\hline & & & &
\end{tabular}

\subsection{ANOVA Testi}

ANOVA, iki veya daha fazla değişken ortalamalarının karşılaştırılmasında kullanılır. Tablo 8'de yer alan verilere varyans analizi uygulanmıştır. Uygulama sonucunda elde edilen çıktılar belirtilmiştir. Yapılan çalışmada;

$H_{0}: \mu_{1}=\mu_{2}$ hipotezi K-Means ve K-Medoids algoritmalarına göre elde edilen maliyetlerin ortalaması aynı olduğu varsayımında bulunur.

$H_{1}: \mu_{1} \neq \mu_{2}$ hipotezi ise K-Means ve K-Medoids algoritmalarına göre elde edilen maliyetlerin ortalaması farklı olduğu varsayımında bulunur.

Varyans analizi uygulama sonucunda analiz edilecek ilk nokta varyansların homojenlik durumudur. Tablo 9' da bulunan Sig. değeri 0,374>0,05 olduğu için değişken varyanslarının homojen olduğu anlaşılmaktadır. Değişken varyansları homojen olması Tablo 10'da bulunan F testinin sonuçlarını doğrulayacaktır. Anova testi sonucunun bulunduğu tablodaki Sig. değeri 0,519>0,05 olmaktadır. Bu durumda $H_{0}$ hipotezi kabul edilmektedir. $H_{0}$ hipotezinin kabulü ile iki algoritmadan elde edilen sonuçlar karşılaştırıldığında istatistiksel olarak bir fark olmadığı söylenebilmektedir. Tablo 11 'de ise üzerinde çalışılan problem için kullanılan algoritmaların çözümünden elde edilen toplam maliyetlerin 
ortalaması bulunmaktadır. 1 numara K-Means algoritmasını temsil ederken, 2 numara ise K-Medoids algoritmasını göstermektedir. Toplam maliyetlerin ortalaması, K-Means algoritmasına göre 112420,86 TL iken K-Medoids algoritmas1 için 113717,43 TL elde edilmiştir. Ulaşılan bilgiler ışı̆̆ında iki algoritmanın benzer performanslarda çalışarak birbirlerine yakın sonuçlar verdiği görülmektedir.

Tablo 9. Varyans değerlerinin homojenlik test sonuçları

\begin{tabular}{llll}
\hline Levene Statistic & df1 & df2 & Sig. \\
\hline, 807 & 1 & 40 &, 374 \\
\hline
\end{tabular}

Tablo 10. Anova testi sonuçları

\begin{tabular}{llllll}
\hline & Sum of Squares & df & Mean Square & F & Sig. \\
\hline Between Groups & 17651523,429 & 1 & 17651523,429 &, 424 &, 519 \\
Within Groups & $166.402 .0763,714$ & 40 & 41600519,093 & & \\
Total & $168.167 .2287,143$ & 41 & & & \\
\hline
\end{tabular}

Tablo 11. Tanımlayıc istatistikler

\begin{tabular}{|c|c|c|c|c|c|}
\hline & & $\mathrm{N}$ & Mean & Std. Deviation & Std. Error \\
\hline 1 & & 21 & 112420,86 & 5093,724 & 1111,542 \\
\hline 2 & & 21 & 113717,43 & 7566,704 & 1651,190 \\
\hline Total & & 42 & 113069,14 & 6404,405 & 988,221 \\
\hline \multirow[t]{2}{*}{ Model } & Fixed Effects & & & 6449,846 & 995,233 \\
\hline & Random Effects & & & & $995,233 \mathrm{a}$ \\
\hline
\end{tabular}

\section{SONUÇ}

Günümüzdeki işletmelerin en önemli hedefleri arasında, müşterilerin isteklerine uygun üretilen ürünlerin hizmeti sağlanırken memnuniyeti en üst düzeye çıkarılması aynı zamanda taşıma maliyetlerinin en az seviyeye indirilmesi yer almaktadır. Amaçların gerçekleştirilebilmesi için araç rotalama probleminin verimli bir şekilde kullanılması gerekmektedir. Araç rotalama problemleri talep edilen ürünlerin depolardan müşterilere taşınması için en uygun rotaların belirlenmesi problemidir. Gün geçtikçe üretim kaynaklarının hızla tükenmesi ile beraber geri dönüşüm faaliyetleri önem kazanmaya başlamıştır. EZTDARP, müşteri talepleri doğrultusunda merkez depodan temin edilen ürünlerle müşterilere hizmet verilirken, müşterilerin iade ettiği ürünler depoya gönderilmesini içermektedir. Dağıtım yapılacak ve toplanacak ürünlerin aynı araçlara yerleştirerek kullanılan araç sayısını ve toplam kat edilen mesafeyi en aza indirecek araç rotalarının belirlendiği problem çeşididir.

Çalışmada, merkez seçilen bir depodan müşterilere taleplerine göre haftalık dağıtım hizmeti verirken eş zamanlı olarak toplama hizmetinin de gerçekleştirildiği rotalama problemi ele alınmıştır. Ele alınan EZTDARP iki aşamalı olarak çözülmüştür. Problemin çözümünün ilk aşamasında müşteriler K-Means ve K-Medoids algoritmaları ile kümelenmiştir. İkinci aşamada ise 1. Aşama sonucunda kümelenen müşteriler için en uygun dağıtım ve toplama rotaları, toplam maliyetini en aza indirmeyi amaçlayan bir tam sayılı doğrusal programlama modeli kurularak belirlenmiştir. Elde edilen sonuçlar ANOVA testi ile karşılaştırılmıştır. Toplam maliyetlerin ortalaması, K-Means algoritmasına göre 112420,86 TL iken K-Medoids algoritması için 113717,43 TL elde edilmiştir. Ulaşılan bilgiler 1şığında iki algoritmanın benzer performanslarda çalışarak birbirlerine yakın sonuçlar verdiği görülmektedir.

$\mathrm{Bu}$ çalışmada ileri sürülen çözüm yaklaşımının gerçek hayat problemlerinde etkin bir şekilde uygulanabileceği düşünülmektedir. Gerçek hayatın içinde, taleplerin sürekli değişimine karşıllık, bu çalışmada önerilen yaklaşım ile, yeni kümeler (eğer gerekiyor ise) oluşturulmakta ve bu küme içindeki müşterilere ulaşmak içinde takip edilecek yeni rotalar yeniden düzenlenebilmektedir. Böylece firma için uygulanacak yeni dağıtım ve toplama politikaları makul derecede kısa sürede (ortalama 15 dakika) belirlenebilmektedir. $\mathrm{Bu}$ da bize önerilen yaklaşımın dinamik rotalama özelliğinin gerçek problemlerin çözümüne ne denli uygun olduğunu göstermektedir.

\section{KAYNAKÇA}

[1] Göksal, F.P., Karaoglan, İ., \& Altıparmak, F. (2013). A hybrid discrete particle swarm optimization for vehicle routing problem with simultaneous pickup and delivery. Computers \& Industrial Engineering, 65(1), 39-53.

[2] Çalış, A., \& Baynal, K. (2016). Kümeleme analizi ile bankacılık sektöründe satış stratejilerinin belirlenmesi, Beykent Üniversitesi. Beykent Üniversitesi Fen ve Mühendislik Bilimleri Dergisi, 9(1), $13-41$.

[3] Laporte, G., \& Semet, F. (2002). Classical heuristics for the capacitated VRP. In: The vehicle routing problem, P. Toth ve D. Vigo (ed.), SIAM Monographs on Discrete Mathematics and Applications, SIAM, Philadelphia, s. 109-128.

[4] Clarke, G., \& Wright, J. W. (1964). Scheduling of vehicles from a central depot to a number of delivery points. Operations Research, 12, 568-581.

[5] Zachariadis, E.E., Tarantilis, C.D. \& Kiranoudis, C.T. (2009). A hybrid metaheuristic algorithm for the vehicle routing problem with simultaneous delivery and pick-up service. Expert System with Applications, 36(2), 1070-1081.

[6] Min, H. (1989). The Multiple vehicle routing problem with simultaneous delivery and pick up points. Transportation Research Part A: General, 23(5), 377-386. 
[7] Dell'Amico, M., Righini, G. \& Salani, M. (2006). A branchand-price approach to the vehicle routing problem with simultaneous distribution and collection. Transportation science, 40(2), 235-247.

[8] Subramanian, A., Uchoa, E., Pessoa, A.A. \& Ochi, L.S. (2011). Branch-and-cut with lazy separation for the vehicle routing problem with simultaneous pickup and delivery. Operations Research Letters, 39(5), 338-341.

[9] Wang, H.F. \& Chen, Y.Y. (2012). A genetic algorithm for the simultaneous delivery and pickup problems with time windows. Computers \& Industrial Engineering, 62(1), 84-95.

[10] Subramanian, A., Uchoa, E., Pessoa, A. \& Ochi, L. (2013). Branch-cut-and-price for the vehicle routing problem with simultaneous pickup and delivery. Optimization Letters, 7(7), 1569-1581.

[11] Dethloff, J. (2001). Vehicle routing and reverse logistics: the vehicle routing problem with simultaneous delivery and pick-up. OR Spectrum, 23, 79-96.

[12] Crispim, J. \& Brandao, J. (2005). Metaheuristics applied to mixed and simultaneous extensions of vehicle routing problems with backhauls. Journal of the Operational Research Society, 56, 1296-1302.

[13] Nagy, G. \& Salhi, S. (2005). Heuristic algorithms for single and multiple depot vehicle routing problems with pickups and deliveries. European Journal of Operational Research, $162,126-141$.

[14] Chen, J. (2006). Approaches for the vehicle routing problem with simultaneous deliveries and pick-ups. Journal of the Chinese Institude of Industrial Engineers, 23(2), 141-150.

[15] Ropke, S., \& Pisinger, D. (2006). A unified heuristic for a large class of vehicle routing problems with backhauls. European Journal of Operational Research, 171, 750-775.

[16] Erbao, C., Minygyong, L. \& Kai, N. (2008). A differential evolution and genetic algorithm for vehicle routing problem with simultaneous pickup and delivery and time Windows. Proceedings of the 17th World Congress the International Federation of Automatic Control, Seoul, Korea, 6-11 Haziran.

[17] Ai, J., \& Kachitvichyanukul, V. (2009). A particle swarm optimization for the vehicle routing problem with simultaneous pickup and delivery. Computers \& Operations Research, 36(5), 1693-1702.

[18] Gajpal, Y., \& Abad, P. (2009). An ant colony system (ACS) for vehicle routing problem with simultaneous delivery and pickup. Computers \& Operations Research, 36, 3215-3223.

[19] Zachariadis, E.E., Tarantilis, C.D., \& Kiranoudis, C.T. (2009). A Hybrid Metaheuristic algorithm for the vehicle routing problem with simultaneous delivery and pick-up service. Expert System with Applications, 36, 1070-1081.

[20] Catay, B. (2010). A new saving-based ant algorithm for the vehicle routing problem. Expert Systems with Applications, 37, 6809-6817.

[21] Cetin, S., \& Gencer, C. (2010). Kesin zaman pencereli eş zamanlı dağıtım toplamalı araç rotalama problemi. Gazi
Üniversitesi Mühendislik Mimarlık Fakültesi Dergisi, 25(3), 579-585.

[22] Mingyong, L., \& Erbao, C. (2010). An improved differential evolution algorithm for vehicle routing problem with simultaneous pick-ups and deliveries and time Windows. Engineering Applications of Artificial İntelligence, 23, 188-195.

[23] Zachariadis, E., Tarantilis, C.D., \& Kiranoudis, C.T. (2010). An adaptive memory methodology for the vehicle routing problem with simultaneous pick-ups and deliveries. European Journal of Operational Research, 202, 401-411.

[24] Goksal, F. P., Karaoglan, İ., \& Altıparmak, F. (2013). A hybrid discrete particle swarm optimization for vehicle routing problem with simultaneous pick up and delivery. Computer Industrial Engineering, 65, 39-53.

[25] Li, J., Pardalos, P.M., Sun, H., Pei, J., \& Zhang, Y. (2015) Iterated local search embedded adaptive neighborhood selection approach for the multi-depot vehicle routing problem with simultaneous deliveries and pickups, Expert Systems with Applications, 42(7), 3551-3561.

[26] Kaya, C. (2017). Eş Zamanlı topla dağıt araç rotalama problemi için karınca koloni sistemi ile güçlendirilmiş değiş̧ken komşuluk arama algoritması. Yüksek Lisans Tezi, Pamukkale Üniversitesi, Türkiye.

[27] Zhua, L., \& Sheub, J.B. (2018). Failure-specific cooperative recourse strategy for simultaneous pickup and delivery problem with stochastic demands. European Journal of Operational Research, 271, 896-912.

[28] Nallusamy, R., Duraiswamy, K., Dhanalaksmi, R., \& Parthiban, P. (2010). Optimization of non-linear multiple traveling salesman problem using k-means clustering, shrink wrap algorithm and meta-heuristics. International Journal of Nonlinear Science, 9(2), 171-177.

[29] Çalışkan, K. (2011). Karınca kolonisi optimizasyonu ile araç rotalama probleminin maliyetlerinin kümeleme tekniği ile iyileştirilmesi. Yüksek Lisans Tezi, TOBB Ekonomi ve Teknoloji Üniversitesi, Türkiye.

[30] Şen, T. (2014). Kümeleme ve genetik algoritma destekli yaklaşımlarla kapasite kısıtlı araç rotalama probleminin çözümü: perakende zincirinde uygulanması. Yüksek Lisans Tezi, Sakarya Üniversitesi, Türkiye.

[31] Boyzer, Z., Alkan, A., \& Fiğlalı, A. (2014). Cluster-first, thenroute based heuristic algorithm for the solution of capacitated vehicle routing problem. International Journal of Informatics Technologies, 7, 29-37.

[32] Cömert, S.E., Yazgan, H.R., Sertvuran, İ., \& Şengül, H. (2017). A new approach for solution of vehicle routing problem with hard time window: an application in a supermarket chain. Sādhanā, 42(12), 2067-2080.

[33] Ünsal, Ö., \& Yiğit, T. (2018). Yapay zeka ve kümeleme teknikleri kullanılarak geliştirilen yöntem ile okul servisi rotalama probleminin optimizasyonu. Mühendislik Bilimleri ve Tasarım Dergisi, 6(1), 7-20. 
[34] Montane, F.A.T., \& Galvao, R.D. (2006). A tabu search algorithm for the vehicle routing problem with simultaneous pick-up and delivery service, Computers \& Operations Research, 33, 595-619.

[35] Lenstra, J.K., \& Kan, A.H.G. (1981). Complexity of vehicle routing and scheduling problems. Networks, 11(2), 221-227.

[36] Sarıman, G. (2011). Veri madenciliğinde kümeleme teknikleri üzerine bir çalışma: k-means ve k-medoids kümeleme algoritmalarının karşılaştırılması. Süleyman Demirel Üniversitesi Fen Bilimleri Enstitüsü Dergisi, 15(3), 192-194.
[37] Grabmeier, J., \& Rudolph, A. (2002). Techniques of cluster algorithms in data mining. Data Mining and Knowledge Discovery, 6(4), 303-360.

[38] MacQueen, J. (1967). Some methods for classification and analysis of multivariate observations. Proceedings of the 5th Berkeley Symposium on Mathematical Statistics and Probability, 1, 281-297.

[39] Kaufman, L., \& Rousseeuw, P.J. (1990). Finding Groups in Data: an Introduction to Cluster Analysis (1. Bask1). Wiley Series in Probability and Statistics. 